\title{
Galactosylation of caffeic acid by an engineered $\beta$-galactosidase
}

\author{
Lili Lu, Yuchuan Guo, Lijuan Xu, Tingting Qi, Lan Jin, Li Xu, Min Xiao* \\ State Key Lab of Microbial Technology and National Glycoengineering Research Center, Shandong University, Ji'nan, China.
}

\begin{abstract}
Summary Glycosylation is useful for improving the chemical properties and physiological functions of biologically and pharmacologically important compounds. The glycosylation of phenolic compounds can increase their solubility and stability in water. The addition of galactose residue has special meaning as it facilitates targeted delivery of drugs to the liver cancer cells with abundant galactose acceptors on the cell surface. In this work, the engineered $\beta$-galactosidase W980F from Lactobacillus bulgaricus L3 was utilized for the glycosylation of caffeic acid, a well-known phenolic phytochemical with broad bioactivities. The reaction was performed by incubation of the enzyme with $200 \mathrm{mM}$ of lactose and $100 \mathrm{mM}$ of caffeic acid at $45^{\circ} \mathrm{C}$ for $1 \mathrm{~h}$. The product was purified and analyzed by MS and NMR spectra. The MS revealed a signal of $[\mathrm{M}-\mathrm{H}]^{-}$at $m / z, 341.09$, suggesting monogalactosylated products of caffeic acid $\left(M_{r}\right.$ 342). The NMR spectra further identified the products to be caffeic acid 3 '- $O$ - $\beta$ galactopyranoside and caffeic acid $4^{\prime}-O$ - $\beta$-galactopyranoside in a ratio of $1: 3$. This was the first discovery that caffeic acid could be galactosylated by the engineered glycosidase.
\end{abstract}

Keywords: Lactobacillus bulgaricus L3, $\beta$-galactosidase, galactosylation, caffeic acid

\section{Introduction}

Caffeic acid, 3,4-dihydroxycinnamic acid, is a wellknown phenolic phytochemical present in plants such as coffee and honey. It reportedly has broad bioactivities including anti-oxidant, anti-cancer, anti-inflammatory, immunomodulatory, neuroprotective and tissue reparative effects $(1-10)$. The clinical and experimental findings demonstrated anticancer properties of caffeic acid against both ER (estrogen receptor- $\alpha$ ) positive and ER negative breast cancer (1). Additional data showed it attenuated solar UV-induced skin carcinogenesis (2) and reduced the risk of patocellular carcinoma caused by hepatitis $\mathrm{C}$ virus (3). Also, caffeic acid inhibited the multiplication of viruses such as influenza A virus, herpes simplex virus, and polio virus (4), and suppressed the growth of bacteria such as Pseudomonas aeruginosa commonly isolated from wound infections $(5,6)$. Besides, caffeic acid exhibited an immunomodulatory action in human monocytes with no cytotoxic effects (7). Moreover, caffeic acid showed inhibitory activity

\footnotetext{
*Address correspondence to:

Dr. Min Xiao, State Key Lab of Microbial Technology and National Glycoengineering Research Center, Shandong University, Ji'nan 250100, China.

E-mail: minxiao@sdu.edu.cn
}

against $\alpha$-synuclein fibrillation, which would be helpful for design of novel therapeutic drugs for Parkinson's disease (8). More importantly, caffeic acid exerted neuroprotective and antidementia effects, at least in part, by preventing the loss of neural cells and synapses in ischemic brain injury $(9,10)$. Despite the broad biological activities, the low stability and poor solubility of caffeic acid reduced its applicability as a pharmaceutical product (6).

Glycosylation is considered to be a very useful method for improving the chemical properties and physiological functions of biologically and pharmacologically important compounds (11-15). The introduction of the glycosyl residue into the phenolic compounds can increase their solubility and stability in water and protect them from oxidation $(11,12)$. Also, glycosylation can improve biological and pharmacological functions, including the decrease of toxicity and side effects, as well as the increase of bioavailability of drugs that need to pass through the blood-brain barrier (11). For instance, hydroquinone is toxic while its glucoside arbutin has antibacterial and skin whitening effects (12). Similar finding is about the eugenol with function as a hair restorer but liable to sublimate, the glucoside of which can be gradually degraded into eugenol by the indigeneous microorganisms of human skin and acts as a pro-drug 
additive in commercial hair-restorers (13). Another example is that the glucosides of quercetin exhibit unexpectedly improved bioavailability (14). In a word, new glycosides of phenolic compounds could have novel pharmacological properties (12).

Variation of the introduced glycosyl residues shows different impact on the properties of phenolic compounds. The galacosylated hydroquinone is 1.19 times higher antioxidant than the glucoside counterpart, arbutin (15). More interestingly, there exist abundant galactose acceptors on the hepatocyte surface that could bind with galactose derivatives (16). Thus, the glycosylation with galactose could aid targeted delivery of drugs to liver cancer cells but not to nearby normal cells. For example, the galatosylated lithocholic acid shows high specificity to mouse liver cells in vivo (17).

Generally, there are two basic classes of methods for the glycosylation (18). One is the chemical method that requires laborious protection and deprotection steps to control the stereo- and regio-specificity of products, along with the use of toxic catalysts and solvents. The other is the enzymatic glycosylation that possesses the advantages of high stereo- and regio-selectivity and can be accomplished in one step under mild conditions. Glycosyltransferases (EC 2.4) and glycosidases (EC 3.2.1) are two classes of enzymes responsible for this application (19). Typically, glycosyltransferases are effective and catalyze stereo/regio-selective reactions, but they have strict substrate selectivity and require costly glycosyl donors in the one-step reactions. As for large-scale synthesis, the glycosidases exhibit obvious advantages including the readily available enzyme source, the simple and inexpensive donor substrates, as well as the wide acceptor tolerance (20).

$\beta$-Galactosidases (EC 3.2.1.23) are among the most important glycosidases that can catalyze the galactosylation process (21). However, only one natural $\beta$-galactosidase from Kluyveromyces lactis was reported to be able to galactosylate hydroquinone (15). The low nucleophilicity of phenolic hydroxyl groups might be related to the difficulty of their glycosylation by the enzymes. In the previous work, the $\beta$-galactosidase from Lactobacillus bulgaricus L3 had been engineered to possess high transglycosylation activity toward a series of single phenolic-ring compounds including phenol, hydroquinone, catechol and pyrogallol (22). In this work, the enzyme was extendedly used to glycosylate the caffeic acid with a more complex phenolic structure, resulting in caffeic acid galactosides potentially with novel pharmacological properties.

\section{Materials and Methods}

\subsection{Strains}

The $\beta$-galactosidase gene from $L$. bulgaricus $\mathrm{L} 3$ had been submitted to GenBank with accession No.
EU734748.1. This gene was inserted into the pET-21b vector (pET-21b-bga) and subjected to site mutation (W980F) in the previous work (22). The Escherichia coli BL21(DE3) carrying the recombinant wildtype and mutant genes were cultured in LB medium containing $10 \mathrm{~g}$ of peptone, $5 \mathrm{~g}$ of yeast extract and $5 \mathrm{~g}$ of $\mathrm{NaCl}$ in $1,000 \mathrm{~mL}$ of water ( $\mathrm{pH} 7.5$ ), supplemented with ampicillin at $100 \mu \mathrm{g} / \mathrm{mL}$. The solid medium additionally included $15 \mathrm{~g} / \mathrm{L}$ agar.

\subsection{Preparation of the $W 980 F$ enzyme}

The $E$. coli BL21(DE3) carrying the recombinant mutant genes was grown in $30 \mathrm{~mL}$ of LB medium containing ampicillin at $37^{\circ} \mathrm{C}$ for $12 \mathrm{~h}$, and then transferred into 1 $\mathrm{L}$ of fresh medium in a 1:100 (v/v) ratio. The enzyme was induced by addition of isopropyl-1-thio- $\beta$-Dgalactoside (IPTG) when the cell density reached 0.61.0 at $600 \mathrm{~nm}$. After continuous cultivation for $3 \mathrm{~h}$, the cells were harvested and disrupted by ultrasonic treatment. The lysate was centrifuged at $12,000 \mathrm{rpm}$ for $30 \mathrm{~min}$ at $4{ }^{\circ} \mathrm{C}$ and the enzyme was purified from the suspension by $\mathrm{Ni}^{2+}$ chelation chromatography. The column with $5 \mathrm{~mL}$ of Ni Sepharose (GE Healthcare) was equilibrated with phosphate buffer $(50 \mathrm{mM}$ sodium phosphate, $500 \mathrm{mM}$ sodium chloride, $\mathrm{pH}$ 7.0). The column was loaded with samples and washed with phosphate buffer and subsequent with washing buffer (50 $\mathrm{mM}$ sodium phosphate, $500 \mathrm{mM}$ sodium chloride, $50 \mathrm{mM}$ imidazole, $\mathrm{pH}$ 7.0). Bound protein was eluted with elution buffer $(50 \mathrm{mM}$ sodium phosphate, 500 $\mathrm{mM}$ sodium chloride, $300 \mathrm{mM}$ imidazole, $\mathrm{pH}$ 7.0). Aliquots of the fractions were run on $10 \%$ SDS-PAGE and stained with Coomassie Brilliant Blue to analyze their purity. Fractions containing the pure protein were pooled, dialyzed and stored at $-20^{\circ} \mathrm{C}$. The wild-type enzyme was prepared with the same procedures.

\subsection{Enzyme and protein assays}

The $\beta$-galactosidase activity was measured by adding $50 \mu \mathrm{L}$ of enzyme solution to $450 \mu \mathrm{L}$ of $2 \mathrm{mM} o \mathrm{NPGal}$. The reaction was performed at $37^{\circ} \mathrm{C}$ for $10 \mathrm{~min}$ and then stopped by adding $1 \mathrm{~mL}$ of $500 \mathrm{mM} \mathrm{Na}_{2} \mathrm{CO}_{3}$. The amount of $o$-nitrophenol released was measured at 420 $\mathrm{nm}$. One unit of enzyme activity (U) was defined as the amount of enzyme required to liberate $1 \mu \mathrm{mol}$ of $o$-nitrophenol per minute under the assay conditions. The amount of protein was quantified by the method of Lowry with bovine serum albumin as the standard.

\subsection{Transglycosylation reactions}

The transglycosylation reactions were performed at $45^{\circ} \mathrm{C}$ for $1 \mathrm{~h}$ in $50 \mu \mathrm{L}$ mixtures ( $\mathrm{pH} 7.0$ ) containing 0.2 $\mu \mathrm{g}$ of pure enzyme, $200 \mathrm{mM}$ of lactose and $100 \mathrm{mM}$ of caffeic acid. The control reactions followed the same 
conditions except for the use of inactivated enzyme. All the reactions were terminated by heating at $100^{\circ} \mathrm{C}$ for 5 min. Glycoside products were detected by TLC and HPLC as described below.

\subsection{TLC and HPLC analysis}

TLC was performed with Silica gel 60 F254 plates (Merck, Germany). The developing solvent was a mixture of $n$-butanol:ethanol:water (5:3:2, v/v/v). Sugars on the TLC plate were detected by spraying with a solution of $0.5 \%(\mathrm{w} / \mathrm{v}) 3,5$-dihydroxytoluene dissolved in $20 \%(\mathrm{v} / \mathrm{v})$ sulfuric acid and subsequent heating at $120^{\circ} \mathrm{C}$ for $5 \mathrm{~min}$. HPLC was performed by Agilent 1200 series equipped with Agilent Zorbax carbohydrate analysis column $(4.6 \times 250 \mathrm{~mm})$. The column temperature was maintained at $30^{\circ} \mathrm{C}$. Samples were eluted with $85 \%$ (v/ $\mathrm{v})$ acetonitrile at a flow rate of $1.0 \mathrm{~mL} / \mathrm{min}$, through a refractive index detector (G1362A) for the sugar analysis or a UV detector (G1314B) at $254 \mathrm{~nm}$ for the analysis of phenolic derivatives. Conversion yield of aromatic product $(\%)$ : [product concentration $(\mathrm{mM}) /$ concentration of lactose used $(\mathrm{mM})] \times 100(15)$.

\subsection{Purification of glycoside products}

Ten milliliters of transglycosylation reactions were performed at $45^{\circ} \mathrm{C}$ for $1 \mathrm{~h}$. The resulting glycosylated products were concentrated by vacuum freeze dehydration. Then, the samples were subjected to a BioGel P2 column $(1.5 \times 100 \mathrm{~cm})$ and subsequently loaded on preparative Silica gel $60 \mathrm{~F}_{254} 1$-mm plates (Merck, Germany) for purification.

\subsection{MS and NMR analysis}

Mass spectra were recorded on a Shimadzu LCMSIT-TOF instrument (Kyoto, Japan) equipped with an ESI source in negative ion mode at a resolution of 10,000 full width at half-maximum. ${ }^{1} \mathrm{H}$ and ${ }^{13} \mathrm{C}$ NMR spectra were recorded at $26^{\circ} \mathrm{C}$ with a Bruker DRX Advance-600 spectrometer (Bruker Biospin $\mathrm{AG}$, Fallanden, Switzerland) at $600 \mathrm{MHz}$ for ${ }^{1} \mathrm{H}$ and $150 \mathrm{MHz}$ for ${ }^{13} \mathrm{C}$. Chemical shifts were given in ppm downfield from internal TMS of $\mathrm{D}_{2} \mathrm{O}$. Chemical shifts and coupling constants were calculated from a firstorder analysis of the spectra. Assignments were fully supported by homo- and hetero- nuclear correlated 2D techniques, including COSY (correlation spectroscopy), HSQC (hetero-nuclear single quantum coherence) and HMBC (hetero-nuclear multiple band correlation) experiments following standard Bruker pulse programs.

\section{Results and Discussion}

The wild-type and mutant (W980F) recombinant $\beta$-galactosidases from $L$. bulgaricus L3 were expressed

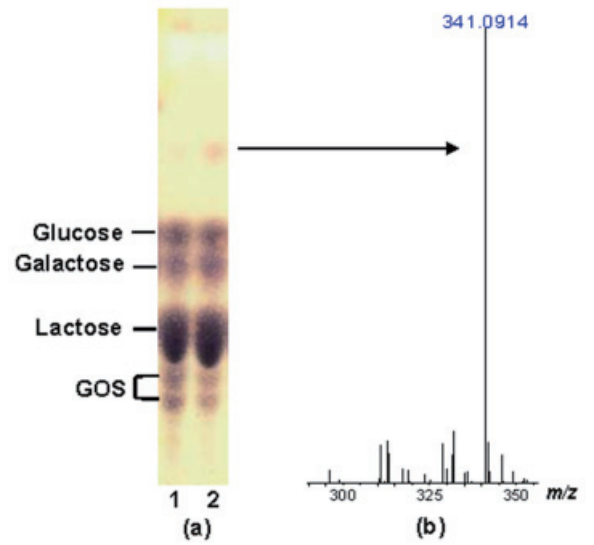

Figure 1. TLC analysis of the transglycosylation reactions catalyzed by wild-type and mutant enzymes (a) as well as MS analysis of the purified novel product (b). Lane 1, reaction catalyzed by the wide-type enzyme; Lane 2, reaction catalyzed by the W980F enzyme.

in E. coli BL21 (DE3), and subsequently purified to electrophoresis purity through $\mathrm{Ni}^{2+}$ chelation chromatography. The ability of their transglycosylation toward caffeic acid were tested by incubation of the enzymes with lactose and caffeic acid at $45^{\circ} \mathrm{C}$ for $1 \mathrm{~h}$. Then the reactions were detected by TLC. As shown in Figure 1a, an obvious novel product spot appeared in the reaction catalyzed by the mutant W980F when compared with that catalyzed by the wild-type enzyme. In the $\beta$-galactosidase-catalyzed reactions, the side products, glucose and galactose, were formed by the enzymatic hydrolysis of lactose, while the prebiotic galactooligosaccharides (GOS) were produced by the enzymatic self-condensation of lactose $(21,22)$. The migration distance of the novel product was larger than the monosaccharides resulting from the hydrolysis reaction, consistent with the characteristic of the phenolic glycoside. HPLC analysis of the reaction mixture revealed a $7 \%$ conversion yield of the new product.

The novel product was purified and analyzed by negative ESI-MS. Figure $1 \mathrm{~b}$ showed a characteristic signal of [M-H] $]^{-}$at $m / z 341.09$, confirming that the newly produced glycoside was monogalactoside $\left(M_{r} 342\right)$ of caffeic acid $\left(M_{r}\right.$ 180). Although the TLC result revealed one spot that was monoglycosylated as determined by MS, NMR analysis of the derivative displayed signals of two products (Figures S1-S5, http://www.ddtjournal. com/docindex.php? year $=2015 \&$ kanno $=2$ ). The signals of galactose were overlapped while those of caffeic-acid residues were separate. In the ${ }^{1} \mathrm{H}$ NMR spectra, chemical shifts of the galactose protons located at $\delta 4.92$ to 3.64 ppm while those of caffeic acid were in the range of $\delta 7.27$ to $6.22 \mathrm{ppm}$ (Figure S1). The anomeric $\mathrm{H}-1$ peaks at 4.92 ppm as well as the coupling constant of $\mathrm{H}-1$ and $\mathrm{H}-2(J$ $=7.8 \mathrm{~Hz}$ ) confirmed the $\beta$-linkage between the sugar and caffeic acid. In ${ }^{13} \mathrm{C}$ NMR spectrum, chemical shifts of the sugar carbons located at $\delta 101.1$ to $60.5 \mathrm{ppm}$ while those 
from $\delta 181.4$ to $114.6 \mathrm{ppm}$ belonged to the caffeic-acid residues (Figure $\mathrm{S} 2$ ).

The complete structural characterization was achieved using 2D-NMR analysis, including ${ }^{1} \mathrm{H}-$ ${ }^{1} \mathrm{H}$ COSY, ${ }^{1} \mathrm{H}-{ }^{13} \mathrm{C}$ HSQC and HMBC experiments, to assign the chemical shifts and configurations. In HMBC, the C-3' $(\delta$ 144.9) and C-4' $(\delta$ 145.9) in two separate phenolic rings displayed correlation signals with the anomeric $\mathrm{H}-1$ of the sugar residue, respectively (Figure S5). Based on the above analysis, the chemical structure of the glycoside products were identified to be caffeic acid 3'-O- $\beta$-galactopyranoside and caffeic acid 4'-O- $\beta$-galactopyranoside, respectively. According to the peak area of phenolic $\mathrm{H}-5^{\prime}$ in the ${ }^{1} \mathrm{H}$ NMR spectra, the ratio of the two products was $1: 3$. Thus, their structure data were summarized in Table 1.

Figure 2 showed the outline of the biosynthesis of these compounds using the engineered $\beta$-galactosidase from $L$. bulgaricus L3. The caffeic acid was galactosylated for the first time via glycosidase-mediated catalysis. Although glycosidases have great advantage of relaxed substrate specificity for acceptors in the enzymatic synthesis, the glycosylation of phenolic compounds were still challenging for these enzymes. The low nucleophilicity of phenolic hydroxyl groups might be responsible for the difficulty in the enzymatic glycosylation when compared to the alcoholic hydroxyl

Table $1 .{ }^{1} \mathrm{H}$ and ${ }^{13} \mathrm{C}$ NMR data assignment for the caffeicacid glycosides produced by the $\mathrm{W} 980 \mathrm{~F}$ enzyme

\begin{tabular}{|c|c|c|c|c|}
\hline \multirow{2}{*}{ C-atom } & \multicolumn{2}{|c|}{ CA-4'-O- $\beta-\mathrm{Gal}^{*}$} & \multicolumn{2}{|c|}{ CA-3'-O- $\beta-\mathrm{Gal}$} \\
\hline & $\delta \mathrm{C}$ & $\delta \mathrm{H}$ & $\delta \mathrm{C}$ & $\delta \mathrm{H}$ \\
\hline $\mathrm{C}-1$ & 101.1 & 4.92 & 101.1 & 4.92 \\
\hline $\mathrm{C}-2$ & 70.3 & 3.72 & 70.3 & 3.72 \\
\hline $\mathrm{C}-3$ & 72.3 & 3.64 & 72.3 & 3.64 \\
\hline C-4 & 68.3 & 3.86 & 68.3 & 3.86 \\
\hline C-5 & 75.4 & 3.73 & 75.4 & 3.73 \\
\hline C-6 & 60.5 & 3.64 & 60.5 & 3.64 \\
\hline $\mathrm{C}-1^{\prime}$ & 130.9 & - & 127.9 & - \\
\hline $\mathrm{C}-2^{\prime}$ & 114.6 & 7.04 & 114.9 & 7.27 \\
\hline $\mathrm{C}-3^{\prime}$ & 145.6 & - & 144.9 & - \\
\hline C-4' & 145.9 & - & 147.3 & - \\
\hline $\mathrm{C}-5^{\prime}$ & 116.0 & 7.02 & 116.5 & 6.82 \\
\hline $\mathrm{C}-6^{\prime}$ & 120.8 & 7.00 & 123.9 & 7.08 \\
\hline $\mathrm{C}-7^{\prime}$ & 175.9 & - & 181.4 & - \\
\hline C-8' & 122.9 & 6.25 & 121.8 & 6.22 \\
\hline C-9' & 140.0 & 7.14 & 140.4 & 7.16 \\
\hline
\end{tabular}

${ }^{*}$ CA, caffeic acid. nucleophiles that are easily glycosylated by the enzymes. Currently, only a few natural glycosidases were discovered to be able to glycosylate phenolic compounds. They were glucose-transferred glycosidases in most cases, such as $\alpha$-amylase (EC 3.2.1.1) and $\alpha$-glucosidase (EC 3.2.1.20) from Bacillus subtilis, Saccharomyces cerevisiae, Xanthomonas campestris and Xanthomonas maltophilia $(12,13,23-25)$. Only one natural $\beta$-galactosidase was available from $K$. lactis for the galactosylation of simple hydroquinone (15).

The $\beta$-galactosidases have attracted particular interest due to their production of promising galactose-containing chemicals, including diverse oligosaccharides, alkyl-glycoside, glycoconjugates and others that play important roles in the industries of food additives, cosmetics, and medicines (21). However, these enzymes still have limitations in the glycosylation of phenolic compounds that have many physiological functions. The $\beta$-galactosidase from L. bulgaricus L3 was proved to be a wonderful tool for glycoside synthesis in the previous work. It could efficiently synthesize galacto-oligosaccharides as well as 6'-galactosyl sucralose with combined functions of prebiotics and sweeters (26-28). In the recent work, the site-saturation mutagenesis of the $\beta$-galactosidase from L. bulgaricus L3 generated a W980F mutant with broadened substrate specificity toward pyrogallol. In this work, the W980F was found to be able to glycosylate caffeic acid, suggesting the change of tryptophan into phenylalanine made it possible for glycosylation of more complex polyphenol structure. The acceptor specificity of the enzyme was further expanded. This was a breakthrough in the galactosylation of unusual acceptors by glycosidases. Also there reported other successful examples of glycosidases engineering that optimized enzyme properties including broadening the acceptor specificity. One example was that the nucleophile variant of cellulase (E197S) from Humicola insolens displayed transglycosylation activity towards flavonoid acceptors, which were not part of its normal substrate (29).

It is also worth noting that glycosylation of the caffeic acid was of great meaning considering that glycosylation of phenolic compounds could bring improved properties such as increased solubility and stability in water (11-15). The solubility of caffeic acid in water as well as its stability toward light irradiation

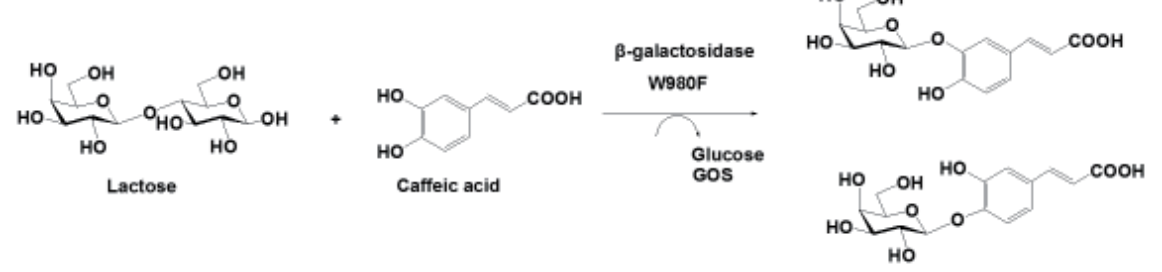

Figure 2. W980F-catalyzed glycosylation of caffeic acid and chemical structures of the glycoside products. 
had been improved by the glucosylation without the loss of any biological activity, such as its antiozidative and antimutagenic properties (23). This confirmed the positive effects of glycosylation on the optimization of phenolic compounds. As properties of glycosides could vary with the type of sugars attached, it is of particular meaning to modify phenolic compounds with novel sugars. The W980F-mediated galactosylation provided an alternative to the existing enzymatic glucosylation method for the modification of caffeic acid. The enzymatic introduction of galactose into the caffeic acid would bring promising properties and widen the scope of their applications such as the design of livertargeted drugs. Thus, the caffeic acid galactosides obtained in this work not only possess inherent values by themselves but also could act as intermediates for further modification to be highly valuable products.

\section{Acknowledgements}

This work was supported in parts by Major State Basic Research Development Program of China (973 Program) (No. 2012CB822102), National High Technology Research and Development Program of China (863 Program) (No. 2012AA021504), National Natural Science Foundation of China (No. 31000035), the Keygrant Project of Chinese Ministry of Education (No. 313033) and Science and Technology Development Project of Shandong Province (No. 2011GSF12104).

\section{References}

1. Rosendahl AH, Perks CM, Zeng L, Markkula A, Simonsson M, Rose C, Ingvar C, Holly JM, Jernström $\mathrm{H}$. Caffeine and caffeic acid inhibit growth and modify estrogen receptor (ER) and insulin-like growth factor I receptor (IGF-IR) levels in human breast cancer. Clin Cancer Res. 2015; 21:1877-1887.

2. Yang G, Fu Y, Malakhova M, Kurinov I, Zhu F, Yao K, Li H, Chen H, Li W, Lim do Y, Sheng Y, Bode AM, Dong Z, Dong Z. Caffeic acid directly targets ERK $1 / 2$ to attenuate solar UV-induced skin carcinogenesis. Cancer Prev Res (Phila). 2014; 7:1056-1066.

3. Tanida I, Shirasago Y, Suzuki R, Abe R, Wakita T, Hanada K, Fukasawa M. Caffeic acid, a coffee-related organic acid, inhibits the propagation of hepatitis C virus. Jpn J Infect Dis. 2015. (DOI:10.7883/yoken. JJID.2014.309)

4. Utsunomiya H, Ichinose M, Ikeda K, Uozaki M, Morishita J, Kuwahara T, Koyama AH, Yamasaki $\mathrm{H}$. Inhibition by caffeic acid of the influenza A virus multiplication in vitro. Int J Mol Med. 2014; 34:10201024.

5. Perumal S, Mahmud R, Ramanathan S. Anti-infective potential of caffeic acid and epicatechin 3-gallate isolated from methanol extract of Euphorbia hirta (L.) against Pseudomonas aeruginosa. Nat Prod Res. 2015; 9:1-4.

6. Pinho E, Henriques M, Soares G. Caffeic acid loading wound dressing: Physicochemical and biological characterization. Ther Deliv. 2014; 5:1063-1075.

7. Búfalo MC1, Sforcin JM. The modulatory effects of caffeic acid on human monocytes and its involvement in propolis action. J Pharm Pharmacol. 2015. (DOI:10.1111/ jphp.12364)

8. Fazili NA, Naeem A. Anti-fibrillation potency of caffeic acid against an antidepressant induced fibrillogenesis of human $\alpha$-synuclein: Implications for Parkinson's disease. Biochimie. 2015; 108:178-185.

9. Pinheiro Fernandes FD, Fontenele Menezes AP, de Sousa Neves JC, Fonteles AA, da Silva AT, de Araújo Rodrigues P, Santos do Carmo MR, de Souza CM, de Andrade GM. Caffeic acid protects mice from memory deficits induced by focal cerebral ischemia. Behav Pharmacol. 2014; 25:637-647.

10. Khan KA, Kumar N, Nayak PG, Nampoothiri M, Shenoy RR, Krishnadas N, Rao CM, Mudgal J. Impact of caffeic acid on aluminium chloride-induced dementia in rats. J Pharm Pharmacol. 2013; 65:1745-1752.

11. Torres P, Poveda A, Jimenez-Barbero J, Parra JL, Comelles F, Ballesteros AO, Plou FJ. Enzymatic synthesis of $\alpha$-glucosides of resveratrol with surfactant activity. Adv Synth Catal. 2011; 353:1077-1086.

12. Prodanović R, Milosavić N, Sladić D, Zlatović M, Božić B, Veličković TĆ, Vujčić Z. Transglucosylation of hydroquinone catalysed by $\alpha$-glucosidase from baker's yeast. J Mol Catal B Enzym. 2005; 35:142-146.

13. Sato T, Takeuchi H, Takahashi K, Kurosu J, Yoshida K, Tsugane T, Shimura S, King K, Kirimura K. Selective alpha-glucosylation of eugenol by alpha-glucosyl transfer enzyme of Xanthomonas campestris WU-9701. J Biosci Bioeng. 2003; 96:199-202.

14. Arts IC, Sesink AL, Faassen-Peters M, Hollman PC. The type of sugar moiety is a major determinant of the small intestinal uptake and subsequent biliary excretion of dietary quercetin glycosides. Br J Nutr. 2004; 91:841-847.

15. Kim GE, Lee JH, Jung SH, Seo ES, Jin SD, Kim GJ, Cha J, Kim EJ, Park KD, Kim D. Enzymatic synthesis and characterization of hydroquinone galactoside using Kluyveromyces lactis lactase. J Agric Food Chem. 2010; 58:9492-9497.

16. Paramjot, Khan NM, Kapahi H, Kumar S, Bhardwaj TR, Arora S, Mishra N. Role of polymer-drug conjugates in organ-specific delivery systems. J Drug Target. 2015; 27:1-30.

17. Gankhuyag N, Singh B, Maharjan S, Choi YJ, Cho CS, Cho MH. Galactosylated poly(ethyleneglycol)lithocholic acid selectively kills hepatoma cells, while sparing normal liver cells. Macromol Biosci. 2015. (DOI:10.1002/mabi.201400475)

18. Sears P, Wong CH. Toward automated synthesis of oligosaccharides and glycoproteins. Science. 2001; 291:2344-2350

19. Desmet T, Soetaert W, Bojarová P, Křen V, Dijkhuizen L, Eastwick-Field V, Schiller A. Enzymatic glycosylation of small molecules: Challenging substrates require tailored catalysts. Chemistry. 2012; 18:10786-10801.

20. Bojarová P, Kren V. Glycosidases in carbohydrate synthesis: When organic chemistry falls short. Chimia (Aarau). 2011; 65:65-70.

21. Oliveira C, Guimarães PM, Domingues L. Recombinant microbial systems for improved $\beta$-galactosidase production and biotechnological applications. Biotechnol Adv. 2011; 29:600-609.

22. Lu L, Xu LJ, Guo Y, Zhang D, Qi T, Jin L, Gu G, Xu 
L, Xiao M. Glycosylation of phenolic compounds by the site-mutated $\beta$-galactosidase from Lactobacillus bulgaricus L3. PLoS ONE. 2015; 10:e121445.

23. Nishimura T, Kometani T, Takii H, Terada Y, Okada S. Glucosylation of caffeic acid with with Bacillus subtilis $\mathrm{X}$-23 $\alpha$-amylase and a description of the glucosides. J Ferment Bioeng. 1995; 80:18-23.

24. Sato T, Nakagawa H, Kurosu J, Yoshida K, Tsugane T, Shimura S, Kirimura K, Kino K, Usami S. $\alpha$-Anomerselective glucosylation of $(+)$-catechin by the crude enzyme, showing glucosyl transfer activity, of Xanthomonas campestris WU-9701. J Biosci Bioeng. 2000; 90:625-630.

25. Chen C, Xiao M, Deng L, Yuan L, Zhang P. An effective way to biosynthesize $\alpha$-glucosyl eugenol with a high yield by Xanthomonas maltophilia. Pharm Biol. 2012; 50:727-731
26. Lu L, Gu G, Xiao M, Wang F. Separation and structure analysis of trisaccharide isomers produced from lactose by Lactobacillus bulgaricus L3 $\beta$-galactosidase. Food chem. 2010; 121:1283-1288.

27. Lu L, Xu S, Zhao R, Zhang D, Li Z, Li Y, Xiao M. Synthesis of galactooligosaccharides by CBD fusion $\beta$-galactosidase immobilized on cellulose. Bioresour Technol. 2012; 116:327-333.

28. Lu L, Xu S, Jin L, Zhang D, Li Y, Xiao M. Synthesis of galactosyl sucralose by $\beta$-galactosidase from Lactobacillus bulgaricus L3. Food chem. 2012; 134:269-275.

29. Yang M, Davies GJ, Davis BG. A glycosynthase catalyst for the synthesis of flavonoid glycosides. Angew Chem Int Ed Engl. 2007; 46:3885-3888.

(Received April 12, 2015; Accepted April 27, 2015) 